Dossiê

\title{
Descolonizando o pensamento social: para ir além de Pierre Bourdieu
}

Jessé Souza ${ }^{1}$

Resumo: O objetivo do artigo é discutir os pressupostos do racismo científico que até hoje comandam silenciosamente a totalidade da produção intelectual hegemônica, principalmente via a chamada teoria da modernização. Mesmo teóricos de alto potencial crítico, como Pierre Bourdieu, por exemplo, repetem procedimentos conceituais típicos da teoria da modernização - que ainda influencia a produção dominante de maneira decisiva - como no seu estudo sobre os trabalhadores da Argélia. O texto pretende, a partir de Bourdieu, investigar os pressupostos pré-reflexivos do debate científico contemporâneo nas ciências sociais e desvelar o núcleo político que distorce a produção de saber.

Palavras-chave: Descolonizando o saber; Bourdieu; Teoria da modernização.

\section{DECOLONIZING SOCIAL THINKING: BEYOND PIERRE BOURDIEU}

Abstract: The aim of this article is to discuss the assumptions of the scientific racism that until today silently commands the totality of hegemonic intellectual production, mainly through the so-called modernisation theory. Even high critical potential theorists, such as Pierre Bourdieu, for example, repeat some of the conceptual procedures typical of the modernisation theory - which still influences the global production of knowledge -, as it is the case in his study on Algerian workers. The

1 Departamento de Políticas Públicas da Universidade Federal do ABC (UFABC) - Santo André - Brasil souza.jesse@uol.com.br 
text intends, departing from Bourdieu, to investigate the pre-reflexive assumptions of the contemporary scientific debate in the social sciences and to unveil the political nucleus that distort the contemporary production of knowledge.

\section{Key-words: Decolonizing knowledge; Bourdieu; Modernisation theory.}

\section{Introdução}

A questão da relação entre o assim chamado "centro" e a assim chamada "periferia" do capitalismo é uma das questões mais espinhosas das ciências sociais. É também uma questão central e ainda sem solução consensual que as acompanham desde o começo. É que o capitalismo sempre foi percebido como uma estrutura econômica de alcance mundial, mas, por outro lado, como possuindo uma estrutura simbólica particular nacional ou regional. O ponto problemático, portanto, não era nem é o alcance da dimensão econômica refletida nas trocas de mercadorias e no fluxo de capitais no capitalismo. A raiz dos problemas é a dimensão simbólica a qual é percebida como não tendo o mesmo alcance e importância que a dimensão econômica. Tudo funciona como se houvesse um mercado econômico capitalista único que abrange todo o planeta e um mundo valorativo e cognitivo diferenciado e multifacetado com múltiplas visões de mundo.

Já Karl Marx havia notado que o capitalismo, ao contrário de todas as sociedades complexas anteriores, não necessita de um quadro de pessoas especializadas na legitimação da ordem vigente, como os mandarins na China Imperial, os brâmanes na Índia ou o clero no Ocidente. Em sua dimensão mais importante, pelo menos, a legitimação da ordem vigente é produzida por uma misteriosa "ideologia espontânea" secretada pelo próprio sistema econômico de modo opaco e sutil (MARX, 1982). A resposta economicista de Marx a essa questão não nos interessa aqui. O importante é sua percepção da "opacidade da dominação" como a marca diferencial do capitalismo e do mecanismo responsável por sua longevidade e por sua extraordinária eficácia cotidiana.

O problemático nessa questão central é que não avançamos muito desde Marx. Vários fatores contribuem para isso. O maior deles é que continuamos sem perceber adequadamente a estrutura simbólica e imaterial subjacente ao capitalismo e responsável por sua "violência simbólica" peculiar. A teoria dominante - remanescente da teoria da modernização americana dos anos 50 do século passado - imagina o capitalismo como uma estrutura institucional "neutra" com relação a valores, a qual se contraporia a uma "cultura" nacional percebida como única realidade simbólica possível. Precisamente por conta disso, ou 
seja, como não se percebe uma estrutura simbólica subjacente a todo o mundo capitalista, imagina-se o mundo como dividido entre "sociedades avançadas", com uma estrutura material e simbólica supostamente própria, e "sociedades atrasadas", com outra estrutura material e simbólica percebida como peculiar e distinta das sociedades avançadas.

A divisão entre culturas avançadas, no centro, e culturas atrasadas, na periferia, foi legitimada "cientificamente" a partir da noção de "estoque cultural" difundida muito especialmente a partir dos anos 20 do século passado (STOCKING, 1998). O "estoque cultural" foi pensado para substituir o "racismo científico" como modo de explicação para a diferença entre os diversos estágios de desenvolvimento entre as diversas sociedades do globo. $\mathrm{O}$ problema é que o culturalismo é uma falsa superação do racismo científico. Na verdade, o culturalismo mantém o racismo e sua separação ontológica entre seres humanos de primeira classe e seres humanos de segunda classe intocada. Pior. Mantém o racismo e todo o seu efeito pernicioso de legitimação pseudocientífica de situações fáticas de dominação dando a impressão de tê-lo superado.

É que o culturalismo é racista nos seus pressupostos implícitos (SOUZA, 2015; 2017). Ele trabalha com a oposição entre corpo/ espírito que cria, no ocidente, uma espécie de "hierarquia moral inarticulada" que comanda silenciosamente todas as nossas ações. Não só as classes sociais se dividem entre "classes do espírito", as classes superiores do capital cultural prestigioso, e as classes do corpo, do trabalho manual, mas também o gênero masculino é associado ao espírito, à inteligência e à moralidade distanciada, enquanto as mulheres são associadas ao corpo e ao afeto. Embora não percebamos na reflexão e na consciência a ação dessa hierarquia, seus efeitos são avassaladores. Das 500 maiores empresas do mundo, 492 são comandadas por homens. Do mesmo modo, o "branco" é associado ao espírito e o "negro" ao corpo e suas virtudes ambíguas como o sexo e a força muscular.

Do mesmo modo, separam-se as "culturas avançadas" do centro, das "culturas atrasadas" da periferia segundo o mesmo critério. O que diferencia o que se chama de "atlântico Norte" da América Latina, por exemplo, é a mesma oposição entre espírito e corpo. A racionalidade e honestidade pressuposta no americano e no Europeu são contrapostas à animalidade afetiva e emocional do latino-americano. Substitui-se a "cor branca" pelo "espírito" e a "cor negra" pela animalidade afetiva e emocional, e temos a mesma distinção ontológica e racista operando como se fosse ciência liberta de preconceitos do senso comum.

Esse "racismo científico" coloniza e distorce a leitura de Max Weber sobre a singularidade do Ocidente baseada na herança protestante ascética. Para Weber, 
o protestantismo era uma "mediação evanescente" do capitalismo, ou seja, teria que morrer para o capitalismo viver (SOUZA, 1997; COHN, 2003). Afinal, o capitalismo precisa do consumo e do hedonismo que eram inimigos no protestantismo. E se a disciplina protestante era requerida para a produção capitalista no início, depois das fábricas e do capitalismo instituído como sistema econômico dominante, todos nós temos de ser disciplinados senão morremos de fome. $\mathrm{O}$ próprio Weber dizia que o protestantismo se transformava em Utilitarismo e, depois, em consumismo e hedonismo. $\mathrm{O}$ esquema era mais ou menos este: $\mathrm{o}$ avô protestante ascético amealha uma grande fortuna que vai ser gerida pelo filho utilitarista e, por fim, consumida pelo neto hedonista.

Na versão culturalista, a leitura weberiana não se aplica apenas à questão da "gênese do capitalismo", como o próprio Weber interpretava sua leitura, mas ela é utilizada para a interpretação da questão muito distinta da expansão do capitalismo para o globo. É assim que Talcott Parsons e seus seguidores da "teoria da modernização" utilizam Weber. Os protestantes ascetas são diligentes, honestos e democráticos, e os outros são particularistas, corruptos e autoritários (PARSONS; SHILLS, 1962). A noção de cultura cívica e de religião civil, por exemplo, do Parsoniano Robert Bellah (1992), espelham esta ideia. A influência dessa leitura até hoje é avassaladora. Não só a leitura dominante de uma sociedade como a brasileira é toda construída como "imagem invertida" do protestante Parsoniano - de Sérgio Buarque até FHC e Roberto DaMatta - mas também não existe contraponto crítico a esta ideia no âmbito das ciências sociais dominantes no "centro" do globo. Outro autor diretamente influenciado por Parsons, como Niklas Luhmann, interpreta a corrupção do "Sul global" pela ação de redes pessoais de relacionamento em um sentido muito semelhante ao proposto pelo antropólogo conservador Robertro DaMatta no Brasil (1978). Como se as mesmas redes de relacionamento pessoal não decidissem também a vida econômica e política também na Alemanha ou nos EUA.

Mas não são só os autores conservadores que são presas fáceis do racismo científico dominante. Um autor como Jürgen Habermas defende em seu livro mais importante que sua teoria comunicativa seria aplicável ao Norte Atlântico, sem se ocupar muito de esclarecer porque as sociedades periféricas não entrariam nessa conta (HABERMAS, 1986). Axel Honneth (1994) fala coisa semelhante acerca de sua teoria. Ora, esta é precisamente a prova mais cabal do efeito generalizador de uma crença implícita que não mais precisa se provar. Conservadores e críticos, cada um a seu modo, a reproduzem. É assim que funciona o racismo científico dominante em todo o planeta. A opacidade da dominação social adentra no debate 
científico e coloniza os próprios termos desse debate, e nos impede de perceber estruturas profundas não só "materiais" mas também "simbólicas" comuns.

Esse "racismo inarticulado" que povoa como um sentimento difuso toda a sociologia desde a sua criação precisa ser reconstruído. Mas, mesmo sendo sociedades modernas do mesmo tipo e com lógicas de funcionamento semelhantes, existem diferenças fundamentais que precisam ser explicadas entre países como França e Alemanha, por um lado, e países como Brasil e México, por outro. A enorme diferença no número de marginalizados e de excluídos, precisamente o problema que interessava a Luhmann em seu texto, entre os países ditos avançados e periféricos, pode e deve ser explicada de modo alternativo ao oferecido pela sociologia até hoje. Por conta disso, vou tentar responder a esses dois desafios articulados neste texto: primeiro, tentar mostrar por que essas sociedades são sociedades do mesmo tipo, para apenas depois tentar determinar as suas diferenças. Em conjunto, a resposta a essas duas questões pode nos ajudar nos primeiros passos do desenvolvimento de uma "teoria crítica da modernização".

\section{A contribuiç̧̃o de Pierre Bourdieu}

Como se podem perceber semelhanças em sociedades aparentemente tão distintas? Acho que a contribuição de Pierre Bourdieu pode ser decisiva aqui. Como se sabe, a "teoria dos capitais" em Bourdieu é o elemento mais abstrato de sua análise das sociedades do capitalismo tardio. Bourdieu percebe os capitais econômico e cultural como os elementos estruturantes de toda a hierarquia social moderna. É fundamental perceber com toda a clareza que isso vale tanto para países como França e Alemanha quanto para países como México, Brasil ou África do Sul. Com isso, quero dizer que toda a luta social por recursos escassos - a questão central para a compreensão da dinâmica profunda de qualquer tipo de sociedade - em qualquer uma das sociedades mencionadas anteriormente, é decidida pelo acesso diferencial a esses capitais impessoais. Esse aspecto é decisivo porque permite a compreensão da luta diária de indivíduos e grupos sociais por todos os interesses materiais e ideais em jogo na vida social. Se a ciência deve, antes de tudo, separar o principal do secundário, não existe aspecto mais importante do que o estudo daquilo que decide sobre as chances de vida de todos nós em todas as dimensões da vida social ou em todos os "campos" sociais, como prefere Bourdieu. Qualquer outro aspecto é, em relação a esse tema, "secundário".

Esse esclarecimento é fundamental para a minha tese: se a articulação entre os capitais impessoais, econômico e cultural, é o ponto de partida para a 
compreensão da dinâmica social moderna - e muito especialmente da hierarquia social que decide sobre quem é superior e quem é inferior nesse tipo de sociedade - como um todo -, então é justo afirmar que sociedades como México, Brasil ou África do Sul são sociedades do mesmo tipo que Estados Unidos, França ou Alemanha. Não há qualquer diferença essencial acerca do modo como se estruturam as classes sociais em luta, por exemplo, no Brasil ou na Alemanha. É o acesso ao capital cultural sob a forma de capital escolar e herança familiar que garante a formação da moderna classe média brasileira como uma classe do "trabalho intelectual" por oposição, por exemplo, ao "trabalho manual" das classes sem acesso significativo ao mesmo tipo de capital. É a mesma diferença que garante a separação - e o acesso a todos os privilégios materiais e ideais envolvidos nessa disputa - entre a classe média alemã e a classe trabalhadora alemã ou composta por imigrantes.

Não há qualquer diferença também - aspecto talvez ainda mais importante - na forma como a "distinção social" é naturalizada e legitimada em ambas as sociedades. Não apenas os capitais impessoais envolvidos no processo de classificação e desclassificação social operam segundo os mesmos princípios, mas também a "violência simbólica" que encobre, distorce e permite a legitimação da dominação social no capitalismo tardio se dá do mesmo modo nas sociedades avançadas e periféricas. Afinal, tanto no Brasil quanto na Alemanha ou na França a naturalização da desigualdade é possível pela sutil violência da "ideologia da meritocracia”. Existem exemplos insofismáveis desse fato na pesquisa empírica, que iremos discutir adiante, acerca da moderna "ralé" brasileira. Como explica Bourdieu, a "ideologia da meritocracia" esconde sistematicamente a "produção social" dos desempenhos diferenciais entre os indivíduos, tornando possível que o desempenho diferencial "apareça" como diferença de talentos inatos.

Se tanto a produção da hierarquia social quanto a produção da dominação social é obtida segundo os mesmos princípios, então a dinâmica da vida social entre as sociedades avançadas e periféricas é fundamentalmente semelhante. A produção artificial de uma "diferença substantiva" entre esses tipos de sociedade tem de ser explicada como um dos mecanismos da própria dominação social em ambas as sociedades, percebidas como de tipo substantivamente diferente. Em Luhmann, o que separaria os dois tipos de sociedade de modo tão essencial seria a presença de "redes de relacionamento" ubíquas e poderosas nas sociedades periféricas, parasitando, para seus próprios fins, tanto a autonomia e o grau de liberdade dos sistemas sociais quanto a capacidade decisória das organizações (LUHMANN, 2008). O pressuposto do argumento de Luhmann 
é, portanto, que não existem "redes de relacionamento" pessoais decidindo o destino dos indivíduos nas sociedades avançadas.

Mais uma vez, Bourdieu pode nos ajudar a esclarecer esse ponto. $\mathrm{O}$ que Bourdieu chama de "capital social" pretende dar conta precisamente do mesmo problema. $\mathrm{O}$ acesso ao capital social de relações pessoais em Bourdieu, no entanto, ainda que seja decisivo para as chances de sucesso individual em qualquer contexto, é percebido como secundário em relação aos capitais impessoais, econômico e cultural. Em outras palavras, o acesso a relações pessoais privilegiadas só é possível a quem já disponha de capital cultural e econômico (ou alguém conhece alguém com acesso privilegiado a relações pessoais vantajosas sem capital econômico ou cultural?). Omitir a ação primordial desses capitais impessoais, como fazem Luhmann, DaMatta e a imensa maioria dos teóricos nesse tema, equivale a omitir a luta de poder e de classes envolvida na apropriação diferencial de capital econômico e cultural. O que "aparece" são apenas pessoas positiva ou negativamente privilegiadas pelo acesso a relações pessoais vantajosas. Pior ainda. Constrói-se uma percepção de sociedades dinâmicas e complexas - ainda que desiguais e injustas -, como a brasileira, que passa a ser percebida como uma sociedade tradicional e pré-moderna, cuja hierarquia social seria construída pelo acesso diferencial a relações pessoais e familiares.

Essas escolhas teóricas não são apenas percepções parciais da realidade sem vinculação com a realidade política. Ao contrário. E na demonstração disso a realidade brasileira pode ser muito informativa. A concentração da atenção nos processos de construção de "redes de relacionamento" para auferir vantagens permanentes, supostamente existentes apenas em sociedades como a brasileira - quando o capitalismo financeiro expõe a corrupção como traço essencial do mercado capitalista em todo lugar -, cria a ilusão de que não existe luta de classes. A opacidade do processo social de apropriação diferencial dos capitais impessoais que irá decidir, a partir do pertencimento de classe, o acesso privilegiado a todos os bens e recursos escassos é reforçada pela opacidade teórica que o torna literalmente invisível e não tematizável. Pior ainda. Constrói-se a ilusão de que esse tipo de aporte teórico permite a crítica de práticas moralmente reprováveis e que aparece, portanto, ao leitor, com o "charminho crítico" de uma leitura crítica da realidade, quando é precisamente seu oposto.

Com isso, criam-se falsos problemas e falsas prioridades, como cruzadas moralistas contra a corrupção, que passam a ocupar o lugar da atenção às questões básicas de distribuição desigual em todas as dimensões. A realidade social não é visível nem compreensível a olho nu. Pode-se ver a pobreza e a miséria de muitos e desconhecer as causas que produzem esse estado. No Brasil, por 
exemplo, o brasileiro médio percebe as mazelas sociais brasileiras como produto da corrupção sistêmica, assim como Luhmann as percebeu.

A "boa consciência" das classes privilegiadas torna-se perfeita, já que o problema está sempre longe, na corrupção estatal, por exemplo, permitindo uma perfeita legitimação de práticas cotidianas de exploração e humilhação. As classes média e alta de uma sociedade como a brasileira não possuem apenas o mesmo privilégio de consumo de seus pares europeus e norte-americanos. No Brasil, essas classes contam ainda com um verdadeiro exército de mão de obra barata sob a forma de empregadas domésticas, babás, faxineiras, porteiros, office boys, motoboys que permite poupar tempo para atividades bem-remuneradas e reconhecidas, além de minorar, por exemplo, a luta de gênero nessas mesmas classes, "transformada" em luta de classes invisível. Chamar a atenção para problemas aparentes ou criar falsas oposições têm sempre o fim de nos cegar em relação a conflitos reais e mais importantes. A percepção de países periféricos dinâmicos como se estes funcionassem como sociedades pré-modernas serve, antes de tudo, para encobrir relações de poder injustas e desiguais.

É precisamente nesse ponto que a obra de Pierre Bourdieu pode, talvez, desempenhar um papel ainda maior do que tem tido hoje em dia. Sua teoria dos capitais pode ser a base de uma nova compreensão do capitalismo global e de seus efeitos díspares em cada contexto peculiar. Ela pode fornecer o fundamento teórico para uma verdadeira teoria crítica da modernidade e da modernização, em que a luta de classes - internacionalmente percebida -, pelo acesso a bens e recursos escassos, tenha a primazia da análise. Julgo que o tema marxista da "ideologia espontânea" do capitalismo possa, desse modo, ser reconstruído de modo mais crítico e teoricamente mais refinado do que foi o caso até agora. No entanto, penso também que existem unilateralidades e falhas importantes no esquema bourdiesiano que devem ser superadas para que este possa ser aproveitado em toda a sua riqueza. O ponto que acho digno de crítica em Bourdieu é o que gostaria de chamar de "contextualismo moral".

Dois textos de Bourdieu são fundamentais para meu escopo aqui: os seus escritos sobre a Argélia e sua obra coletiva sobre a miséria do mundo (BOURDIEU, 1979; 2001). Os escritos sobre a Argélia são especialmente interessantes, posto que Bourdieu está, nesse livro, combatendo precisamente os mesmos "inimigos" de qualquer teoria ou aporte crítico: o modelo econômico racional, implícito em todas as variantes antigas ou modernas da teoria da modernização - que pressupõe adaptações automáticas à "racionalidade" econômica - assim como as formas da época assumidas pelo "culturalismo" antropológico. Já nesse estudo encontramos como categoria "prática", ainda que não desenvolvida em todas 
as suas virtualidades, a grande contribuição, para mim pelo menos, de Bourdieu ao debate sociológico: a percepção de que a sociedade é dividida em grupos sociais com acesso diferencial a disposições para o comportamento prático, assimiladas insensivelmente por meio da educação implícita e explícita.

Essa noção de classe social como aprendizado, em grande medida inintencional, de disposições para crer e agir, põe a percepção da vida social de sociedades modernas verdadeiramente em outro patamar de refinamento teórico e empírico. Foi essa percepção da centralidade da noção de classe social, assim compreendida, que permitiu perceber a dinâmica das lutas de uma sociedade complexa - como a sociedade francesa estudada em $A$ distinção - de modo absolutamente novo, crítico e desilusionista. A novidade estava em perceber a atuação - não perceptível intencionalmente pelos atores envolvidos - de uma lógica de solidariedades e preconceitos, destinada a legitimar o acesso privilegiado e permanente a bens e recursos escassos, produzida subliminarmente e apenas perceptível aos envolvidos nos seus efeitos.

No caso da Argélia colonial estudada por Bourdieu, o argumento central do livro se refere, também, já desde essa época, às condições variáveis de incorporação das "disposições do cálculo econômico", entendida então e ainda hoje como efeito automático da introdução da economia monetária. Bourdieu compreende que noções "naturalizadas" pela percepção cotidiana como "universais" - apenas por serem apropriadas de modo implícito e invisível pela educação das classes médias e privilegiadas - são aquelas que vão fundamentar a existência de uma fronteira entre os adaptados à ordem social dominante e os setores inadaptados, condenados à pobreza e à humilhação social cotidiana. Assim, a ideia central da apropriação diferencial, definida pelo pertencimento à classe social, das disposições associadas à noção de "temporalidade" - como a possibilidade do cálculo econômico, a capacidade de previsão ou ainda a capacidade de projetar um futuro alternativo - é decorrente não do milagre do "mérito individual", mas das precondições sociais que a possibilitam. Aos meus olhos, não existe nenhuma ideia mais importante do que essa no horizonte da teoria social crítica, pela simples razão de que apenas ela permite a desconstrução crítica do arcabouço legitimador de todas as formas de desigualdade social em condições modernas.

Não obstante, existem também deficiências importantes na perspectiva bourdiesiana, e elas podem ser percebidas desde os textos sobre a Argélia, assim como no decorrer de toda a sua obra. Ainda que Bourdieu seja um crítico perspicaz das teorias da modernização - dominantes à época de seu estudo na Argélia, e ainda hoje sob formas mascaradas, inclusive no texto luhmanniano 
comentado anteriormente -, ele termina sendo vítima de algumas das pressuposições típicas das próprias teorias da modernização, como a pressuposição da "transitoriedade" da condição subproletária - ou seja, daquela classe à qual faltam os pressupostos "invisíveis" para o sucesso econômico e social - no capitalismo. Essa tese não é explicitada enquanto tal por Bourdieu, mas a sua perspectiva a pressupõe. Afinal, os subproletários argelinos são percebidos como fruto do êxodo rural para a cidade - um dos topos mais típicos da teoria da modernização - e da disparidade de códigos sociais vigentes em cada um desses universos.

Uma pergunta central nunca colocada, muito menos respondida, nesse contexto, é a que permitiria explicar a permanência da condição subproletária no tempo. Como em várias das análises bourdiesianas, a extraordinária acuidade em se perceber o "contexto" pragmático das lutas sociais, que consome toda sua energia teórica e empírica, o impede de perceber "constantes universais" pelo menos tão universais quanto o capitalismo - que permitiriam apreender o contexto particular e concreto como manifestação sempre diferenciada na sua manifestação efetiva, mas informada por uma lógica semelhante. Isso não deixa de ser surpreendente num autor que logrou desvelar como poucos o "DNA simbólico" que garante e legitima a reprodução infinita dos privilégios sociais no capitalismo.

Se a atenção ao contexto é fundamental - afinal, é neste que a luta e o conflito se realizam e se mostram de modo mais direto e imediato, como a obra de Bourdieu atesta tão bem - a "prisão ao contexto", por outro lado, impede a percepção de uma hierarquia social universalizante e abrangente, ainda que ela se apresente, em cada contexto peculiar, com acentos e nuances distintos. Se a atenção ao contexto permite perceber os "efeitos" de uma moralidade incorporada nos agentes subjetivamente, a prisão ao contextual, por outro lado, nos cega em relação a uma moral objetivada em instituições e, por isso mesmo, eficaz independentemente de contextos particulares, ainda que varie na sua forma fenomênica de acordo com esses mesmos contextos.

Onde se apresenta essa "moralidade contextual" na obra de Bourdieu e de que modo concreto ela pode ser percebida como uma limitação fundamental de sua abordagem? Ainda que Bourdieu fale diversas vezes na sua obra-prima $A$ distinção sobre a oposição alma/ corpo como fundamento de percepções de classe antagônicas, ou no livro sobre a "dominação masculina" como fundamento da oposição homem/ mulher, não existe uma reconstrução dessa hierarquia valorativa como uma estrutura institucional objetiva transcultural, transclassista e transexista que afete os contextos da luta de classes e da luta entre gêneros em 
todas as "culturas" capitalistas. Por que não unir e vincular os "efeitos" contextuais de uma hierarquia moral incorporada subjetivamente e percebida como atuante empiricamente em diversos contextos a uma mesma gênese institucional que afeta, obviamente com importantes diferenças contextuais, todas as sociedades capitalistas modernas, sejam elas centrais ou periféricas?

Bourdieu me parece o interlocutor ideal e privilegiado para se discutir essa questão fundamental na medida em que seu trabalho empírico, muito especialmente nos estudos sobre a Argélia ou sobre "a miséria do mundo", nos permite encontrar situações contextuais e concretas que podem ser explicadas segundo uma lógica objetiva e institucional que é eficaz em todos os casos estudados. Bourdieu, no entanto, não deu esse passo teórico. Os estudos sobre a Argélia permanecem um estudo isolado de um caso particular. Também os estudos realizados em A miséria do mundo, em vários países interessantes e provocativos como eles são, na verdade não dão o salto qualitativo de explicitar a lógica moral e política mais abstrata e geral subjacente aos processos contextuais e concretos analisados.

Ainda que Bourdieu tenha fornecido instrumentos valiosos para essa empreitada, minha opinião é que ele não logrou reconstruir a lógica geral e abrangente dos fenômenos que percebia, contextualmente, tão bem. A reconstrução dessa lógica abstrata e geral é fundamental para mim, posto que apenas ela pode permitir construir uma "teoria crítica da modernização" em todos os rincões do planeta em que a lógica da modernização capitalista logrou se institucionalizar. É essa lógica, afinal, que pode superar o “jogo de espelhos” entre uma teoria da modernização ainda dominante sob outras formas "práticas" políticas de órgãos mundiais, no senso comum culto de sociedades centrais e periféricas - e suas imagens especulares "politicamente corretas", com as quais divide, na realidade, todos os pressupostos teóricos e metateóricos principais.

Acima de tudo, o esquecimento da luta de classes e sua substituição por conceitos compósitos que ofuscam conflitos e contradições, como nação, cultura, região ou civilização. Assim sendo, para demonstrar como essa lógica abstrata e geral do capitalismo, que se expande para todo o globo, implica uma luta de classes global, é necessário reconstruir e expandir o ponto de partida contextual bourdiesiano, adicionando-lhe uma dimensão não contextual, objetiva e universal que Bourdieu não levou às últimas consequências por razões internas ao seu ponto de partida teórico.

Nos seus estudos sobre a Argélia, Bourdieu cita, muito sintomaticamente, a ideia weberiana de que o capitalismo produz e exige um "cosmos" específico, ou seja, um ethos, um conjunto de disposições para crer e agir que é pressuposto 
de qualquer comportamento "bem-sucedido" em um contexto capitalista. Esse tema é fundamental porque em todas as abordagens liberais e politicamente corretas ou esse pressuposto é esquecido - o homo economicus liberal é generalizado como se suas disposições fossem de todas as classes - ou se intenta "defender culturas oprimidas" como se não houvesse um contexto objetivo que as torne "objetivamente desvalorizadas", independente da "vontade", supostamente benévola, de quem quer que seja. Desse modo, a reconstrução "genética" - posto que hoje em dia "esquecida" e naturalizada no senso comum cotidiano - desse ethos ou "cosmos" me parece o maior desafio de uma teoria crítica com ambições globais.

E como se pode mostrar a lógica global de uma luta de classes mascarada e tornada invisível precisamente pela percepção fragmentária e contextual que só identifica noções compósitas como "nações", "culturas" e "regiões" - onde a contradição e o conflito já foram eliminados desde o início - como realidades primárias? Aos meus olhos, a crítica social tem que começar demonstrando que a classe perdedora da universalização do capitalismo por todo o globo - que não é a classe trabalhadora como pensava Marx - obedece a uma lógica semelhante, seja nos países centrais seja nos países periféricos. Isso é fundamental, posto que não existe preconceito maior do que aquele que divide sociedades avançadas e sociedades periféricas como se essa diferença fosse de "substância", ou seja, de tipos de seres humanos distintos, uns mais refinados e outros mais primitivos, corruptos, sensuais etc.

A mesma divisão que habita cada sociedade concreta e separa classes superiores e inferiores, incorporando a divisão entre virtudes não ambíguas da "alma" e virtudes ambíguas do corpo - falarei mais sobre isso adiante -, também está pressuposta nas relações globais em todos os níveis. Muito especialmente na "ciência" - instância legitimadora de todas as práticas no mundo moderno -, em que os teóricos do centro são percebidos como aqueles que possuem cérebro e podem "pensar" teoricamente e os teóricos periféricos só têm olhos e não cérebro e, portanto, apenas "veem" o "dado empírico" - a "ciência" reproduz o esquema da esfera econômica dos países que detêm tecnologia e dos que exportam matéria-prima - que vai ser pensado por pensadores do centro. $\mathrm{O}$ resultado é uma cegueira global que explica por que os conceitos centrais são sempre "regionais" - na realidade norte-atlânticos e não "nacionais", como pensam alguns - e os conceitos "periféricos" sempre especularmente "reativos" e também regionalizados.

No entanto, é possível mostrar, empírica e teoricamente, como existem "classes sociais globais", ou seja, classes sociais que compartilham de uma gênese social e de um destino social semelhante. $O$ primeiro ponto a ser desenvolvido 
é evitar a prisão contextual que só nos dá olhos para a experiência concreta e imediata e nos cega em relação às relações mais abstratas e mais gerais que conformam todos os contextos particulares. $O$ próprio Bourdieu nos dá uma pista dessa hierarquia moral mais abstrata e mais ampla ao nos falar da oposição alma/ corpo como uma oposição moral que articula e determina vários contextos de reprodução da desigualdade social, como nos exemplos da luta de classes e das relações de gênero.

Esse ponto fundamental, no entanto, não é desenvolvido por Bourdieu. Ele exigiria uma reconstrução genética, histórica e conceitual, das precondições de eficácia de uma hierarquia moral que passa a abranger todas as dimensões da vida social. Porém, apesar de usar distinções de caráter moral o tempo todo, esse tema é uma "batata quente" nas mãos de Bourdieu na medida em que justificações morais, em seu esquema explicativo, tendem a ser reduzidas a formas de violência simbólica e mera justificação de situações fáticas de dominação.

Essa redução parece advir de uma escolha consciente em Bourdieu: ainda que ele perceba que existem consensos morais compartilhados por todas as classes em luta por recursos escassos - como a entronização da competição pacífica, por exemplo, mostrada por Norbert Elias (1986), a partir da criminalização do assassinato como meio legítimo de auferir vantagens sociais - ele parece aderir a certo perspectivismo moral, talvez como forma de denunciar seu uso instrumental e interessado. Em princípio, no entanto, não parece existir qualquer incompatibilidade em perceber a eficácia de hierarquias morais que constrange a todos e perceber e criticar seu uso como violência simbólica. Ao meu ver, é precisamente a miopia, em relação à eficácia das hierarquias morais que nos guiam e constrangem a todos, que condena toda análise ao contexto particular e concreto. A própria oposição moral alma/ corpo, tantas vezes citada por Bourdieu, na verdade exige um esforço reconstrutivo prévio para que possa ser utilizada em todo seu alcance.

\section{Para uma teoria crítica da modernização}

Ao meu ver, ninguém melhor que Charles Taylor (1989) reconstruiu essa hierarquia moral subjacente da qual percebemos apenas seus efeitos. Eu percebo o livro As fontes do self, de Taylor, como uma reconstrução da sociologia moral subjacente ao mundo moderno. Longe de uma mera "história das ideias", o que Taylor nos apresenta é uma genealogia da eficácia social de certas "ideias morais". O seu terreno é, portanto, empírico e sociológico. Assim, não foi a leitura das obras de Platão - o primeiro grande sistematizador da oposição alma/ 
corpo como núcleo da hierarquia moral que dominaria o Ocidente - que transformou corações e mentes de pessoas comuns que sequer sabiam ler, mas a institucionalização da noção de virtude platônica por Santo Agostinho como o caminho de salvação de todo cristão. Foi, portanto, a ligação da noção de virtude como controle das paixões do corpo ao "interesse" ideal na salvação da alma que permitiu que toda uma nova "moralidade prática", um novo ethos, no sentido de Max Weber, pudesse ser construído.

A revolução protestante ascética apenas radicaliza essa nova hierarquia valorativa e elimina os compromissos e hesitações que impediam a realização efetiva dessa ideia em muitos contextos sociais. As instituições fundamentais do novo mundo secular, acima de tudo mercado e Estado, vão implementar precisamente a mesma hierarquia valorativa de modo agora opaco e implícito, ao contrário do discurso religioso articulado e explicitado. Se antes a virtude religiosa era definida pelo controle da alma sobre o corpo e suas paixões como caminho para a salvação no "outro mundo", agora, no contexto secularizado, é o controle da "mente" - definição secularizada de "alma" - sobre o corpo que decide sobre as chances de "salvação", definida como sucesso mundano - "nesse mundo". Afinal, o que o capitalismo efetivamente democratiza, pelo menos em alguma medida significativa se compararmos com as sociedades tradicionais, é o acesso ao "conhecimento" e às várias formas de capital cultural. A propriedade econômica continua passando por vínculos de sangue de uma geração a outra como em qualquer sociedade tradicional.

No entanto, e aqui reside o nó górdio da questão, a incorporação de capital cultural não está ao alcance de todos nem é acessível a todas as classes sociais do mesmo modo. O que Taylor chama de "self pontual" - o self capaz de autorremodelação constante pela autodisciplina e autocontrole em nome de necessidades do mercado e do Estado - é um tipo social de classe, tipicamente burguês. Nas sociedades que lograram uma efetiva generalização desse habitus de classe burguês também para as classes inferiores, é onde temos o princípio da igualdade legal mais institucionalizado. Afinal, o self pontual é a base tanto para a noção de produtor útil - e do trabalho como dimensão mais importante do reconhecimento social e da própria autoestima - quanto para a noção de cidadania. A localização e explicitação desses princípios podem nos ajudar a identificar os mecanismos operantes, de forma opaca e implícita, na distinção social entre classes e grupos sociais diversos em sociedades determinadas. Elas podem nos ajudar a identificar os "operadores simbólicos" que permitem, a cada um de nós, na vida cotidiana, hierarquizar e classificar as pessoas como mais ou menos, como dignas de nosso apreço ou de nosso desprezo. 
A generalização do habitus burguês abre espaço para uma nova e revolucionária noção de hierarquia social que passa a ter por base o "self pontual" tayloriano, ou seja, uma concepção contingente e historicamente específica de ser humano presidido pela noção de calculabilidade, raciocínio prospectivo, autocontrole e trabalho produtivo como os fundamentos implícitos tanto da sua autoestima quanto do seu reconhecimento social. Assim, ao contrário do critério hierarquizador da civilização hindu, por exemplo, na qual o princípio da pureza ritual classificava e classifica as distintas castas sociais, no Ocidente passa a ser o compartilhamento de uma determinada estrutura psicossocial o fundamento implícito do reconhecimento social. Essa estrutura psicossocial é o pressuposto da consolidação de sistemas racionais-formais como mercado e Estado, e depois produto principal da eficácia combinada dessas instituições. É essa estrutura psicossocial, também e mais importante, que permitirá ou não a possibilidade de incorporação das predisposições que são fundamentais para o acesso aos capitais econômico e cultural que definem, por sua vez, todas as chances relativas de acesso aos bens e recursos escassos em luta na sociedade.

0 problema é que o habitus burguês definido na noção de self pontual não se generaliza do mesmo modo para todas as classes. Isso significa que a pressuposição de "dignidade" que ele constrói é apropriada diferencialmente pelas diversas classes. $O$ tema se torna ainda mais complexo se lembramos que além da "dignidade" do produtor útil potencialmente acessível a todos, temos também outra fonte de autoestima e reconhecimento social que não é universalizável: a "autenticidade", que enfatiza a "singularidade" da personalidade individual não generalizável por excelência. Essa questão é fundamental para a produção da "distinção social", muito especialmente na sua forma "pastiche" veiculada pela indústria cultural. Mas não é um tema que possamos aprofundar neste contexto. Aqui me interessa demonstrar a eficácia universal, para além de qualquer contexto particular ou nacional, da noção de "dignidade" como pressuposto da autoestima e do reconhecimento social em qualquer contexto capitalista moderno, seja no centro seja na periferia. Para além das lutas de classe que possibilitam acesso diferencial à luta pelos recursos e bens escassos, existe um limite "abaixo da dignidade" que caracteriza porção extremamente significativa da população mundial em todos os lugares.

Ainda que essa classe "abaixo da dignidade" seja comparativamente pequena nos países avançados, ela continua aumentando em todos os lugares. Em países como o Brasil ela representa $1 / 3$ da população. Na maior parte da África essa proporção talvez chegue a $80 \%$. O discurso fragmentário, contextualizado, muitas vezes teoricamente pobre e empiricamente superficial sobre as classes 
subproletarizadas, tem evitado que percebamos sua característica global e universal. O que gostaria de chamar, provocativamente, de "ralé" é precisamente a classe não apenas sem acesso aos capitais que propiciam a incorporação da moderna ideia de "alma", ou seja, dignidade e realização expressiva, mas sem acesso aos pressupostos dessa incorporação. Essa classe é mundial e talvez seja, numericamente, uma das mais significativas.

Em nossa pesquisa empírica sobre os desclassificados sociais brasileiros que chamamos provocativamente de "ralé brasileira" (SOUZA, 2017) - num país que insiste em "maquiar" e tornar invisível essa realidade - foi possível perceber a articulação entre as dimensões "material" (a pobreza econômica) e "simbólica" (os efeitos permanentes do processo de não reconhecimento social) do processo de desclassificação social típico das sociedades modernas. Normalmente, apenas se percebe a pobreza material e se desconhece a realidade simbólica que a legitima e a torna permanente. É claro que essas duas realidades são inseparáveis. Ao mesmo tempo, elas são analiticamente diferentes, o que significa que é necessário compreendê-las na sua interdependência mútua de modo a esclarecer esse fenômeno complexo. A articulação das teorias de Taylor e Bourdieu serve precisamente para iluminar a dimensão simbólica da exclusão social e explicar a permanência no tempo da precariedade material, existencial e política. Afinal, é apenas a legitimação simbólica da desigualdade que a torna aceitável e possível de se reproduzir no tempo.

Como não existe - certamente no Brasil, mas, também, em grande medida no mundo todo - nem a percepção sociológica nem política da realidade simbólica "invisível" que permite tornar permanente a pobreza material "visível", combatem-se "moinhos de vento" construídos a partir da percepção fragmentada da realidade social: a percepção da violência criminosa tornada espetáculo televisivo (que esconde a violência cotidiana mais importante e menos visível); a tendência mundial de tornar a pobreza novamente questão de polícia e retirá-la da dimensão política; a tendência geral de culpar a vítima por sua própria exclusão etc.

Nesse sentido, e essa é uma das vantagens nada desprezíveis do tipo de enfoque que estamos defendendo neste texto, compreender a realidade da exclusão social de grandes segmentos da população em países como o Brasil ajuda a perceber o mesmo tipo de problema em países ditos "avançados" nos quais a dimensão do problema social é, comparativamente, menor. Ao se separarem em categorias analíticas distintas sociedades modernas avançadas e sociedades pré-modernas periféricas, constroem-se no fundo distinções "racistas", posto que substancializadas e essencializadas. Não importa se a explicação "científica" 
dominante opera essa divisão como sendo de fundo abertamente "racial", como no Século XIX, ou como uma linha divisória "cultural", como nos Séculos XX e XXI. O importante aqui é mostrar o caráter falso e artificial desse tipo de operação político-científica. A produção da exclusão e marginalidade em sociedades como a brasileira não se distingue "qualitativamente" do mesmo fenômeno em sociedades ditas avançadas, como os Estados Unidos e a Alemanha.

Essas classes de desclassificados sociais são construídas por motivos "modernos" e semelhantes em qualquer lugar. Afinal, é a ausência da incorporação dos modernos capitais impessoais, tanto o capital econômico quanto o capital cultural, que reduz os indivíduos dessa classe a "corpos" que são vendidos "enquanto corpos", a baixo preço, para serviços desvalorizados. Esses serviços desvalorizados são, tipicamente, divididos em serviços sujos e pesados para os homens reduzidos à energia muscular, e serviços domésticos e sexuais para as mulheres também reduzidas a corpos que não incorporaram conhecimento útil nos mercados competitivos. É, por sua vez, a não incorporação desses capitais impessoais que implica uma realidade simbólica existencial e política precária para aqueles situados abaixo da linha divisória da "dignidade", no sentido tayloriano. Essa condição peculiar implica várias armadilhas para a análise científica, que não são privilégio de brasileiros ou de cientistas da periferia. Também em nível mundial a realidade dos excluídos é tornada invisível pelos mesmos "inimigos": a percepção liberal da sociedade que universaliza as disposições de comportamento da classe média para todas as classes subalternas, permitindo "culpá-las" pelo próprio fracasso e, por outro lado, a percepção "politicamente correta" que assume o discurso do excluído sobre si mesmo como sua verdade.

Os estudos "politicamente corretos" são especialmente insidiosos, posto que se pretendem "críticos" e de "esquerda". No entanto, a descrição do excluído abaixo da condição de "dignidade" sobre sua própria condição é necessariamente "reativa", ou seja, tende a negar subjetivamente a condição subumana que vive objetivamente em seu cotidiano. $O$ distanciamento reflexivo da própria condição só é possível para quem tem acesso à possibilidade de mudar a própria vida. Para quem não tem acesso a "outros possíveis" resta fantasiar ou negar a própria realidade. No entanto, essa perspectiva é francamente dominante nos estudos sobre os excluídos tanto no Brasil quanto mundo afora.

Em nossa pesquisa empírica, realizada entre 2004 e 2008, levada a cabo em diversas regiões brasileiras, desenvolvemos um método empírico original baseado nas pesquisas de Pierre Bourdieu na Argélia e na França. Essa metodologia resultou em entrevistas sucessivas com os mesmos entrevistados de todos os tipos sociais que compõem a "ralé brasileira". Se nas primeiras entrevistas a vida 
familiar era invariavelmente pintada em tons cor-de-rosa, com pais amorosos e dedicados, as entrevistas subsequentes permitiam mostrar rachaduras cada vez mais visíveis no idílio construído pelos excluídos sobre sua própria realidade. Assim, os pais amorosos e dedicados eram substituídos paulatinamente, em muitos dos casos estudados, por pais ausentes ou abusadores sexuais das filhas e filhos, e por mães instrumentais e competidoras das filhas. $\mathrm{O}$ aproveitamento consequente de uma metodologia de pesquisa empírica autorreflexiva e crítica nos permitiu, por meio do aproveitamento das lacunas e das contradições do discurso dos indivíduos dessa classe, "reconstruir" - apesar do autoengano compreensível de quem não tem defesa contra a própria humilhação social de que é vítima - o sentido da vida em condições extremas de exclusão social, nas quais vive cerca de $1 / 3$ da população brasileira.

Esse sentido parece ser construído, em primeiro lugar, na reprodução da "família desestruturada”, fruto da cegueira do debate científico e público dominante e do consequente abandono político dessa classe. A naturalização do abuso sexual dos mais velhos e mais fortes em relação aos mais novos e mais fracos especialmente das meninas, mas, também, dos meninos - chocou todos os pesquisadores envolvidos na pesquisa. Esse tema é um tabu quase nunca veiculado pela mídia, o que apenas favorece a sua perpetuação no tempo. De um modo mais geral, uma atitude abertamente instrumental de todos em relação a todos no interior das famílias dessa classe não é incomum. As feridas na autoestima e na autoconfiança dos indivíduos dessa classe, resultantes dessa prática que se transmite de geração a geração, cuidadosamente ocultada por um acordo silencioso entre vítimas e algozes, não são difíceis de serem imaginadas. Também os papéis sociais de pais e filhos com as obrigações recíprocas da família burguesa de classe média são apenas precariamente reproduzidos. Nesse contexto, adquire todo sentido a retomada, por Axel Honneth, da importância das relações afetivas e emotivas familiares como pressuposto para o exercício de toda função pública, seja como produtor útil seja como cidadão (1994). O abandono social e político das famílias marcadas pelo cotidiano da exclusão parece ser o fator decisivo para a reprodução indefinida dessa classe social no tempo.

Outro fator fundamental ligado ao problema discutido anteriormente é o não aprendizado de habilidades e capacidades fundamentais para a apropriação de capital cultural de qualquer tipo. No relato de vários de nossos informantes, não faltou a presença da instituição escolar. No entanto, era muito comum a observação de que, quando crianças, eles ficavam fitando o quadro negro durante horas sem nada aprender. Com a repetição desse tipo de relato, que nos desconsertou no começo, aprendemos a perceber que o problema em jogo era a 
ausência da incorporação afetiva da "capacidade de se concentrar", algo que os indivíduos de classe média tendem a perceber como uma "habilidade natural", como se simplesmente nascêssemos com ela, como acontece com a capacidade de enxergar ou ouvir. Como faltavam exemplos afetivos em casa, tornados possíveis pelo processo de identificação paterna e materna, essa capacidade ou disposição de se concentrar não era desenvolvida.

Mesmo nas famílias mais bem-estruturadas dessa classe, nas quais os pais permaneciam juntos e se esforçavam para ter uma relação afetiva e de cuidado com os filhos, as marcas do abandono social se mostraram presentes. Como nunca se via o pai lendo um jornal, mas apenas fazendo serviços braçais e brincando com os filhos com os instrumentos desse tipo de trabalho, que tipo de sucesso escolar poder-se-ia esperar dessas crianças? Ou quando a mãe os instava para estudar dizendo que apenas a escola poderia mudar a vida para melhor: que efeito possui esse tipo de exortação se a própria mãe, que havia tido algum tempo na escola, não havia conseguido mudar a própria vida? Percebemos claramente com nossos informantes que não são os "discursos", proferidos da boca para fora, mas apenas as "práticas" sociais efetivas, moldadas por exemplos efetivos, os verdadeiros instrumentos de mudança individual e social.

A instituição escolar, nesse contexto, é ineficiente porque essas crianças já chegam como "perdedoras" nas escolas, enquanto as crianças de classe média já chegam "vencedoras" pelo exemplo e estímulo paterno e materno afetivamente construído. Mas não apenas isso. A instituição escolar pública - cada vez mais precária no Brasil e crescentemente também nos países ditos avançados - passa a ser marcada pela "má fé institucional", no sentido em que Bourdieu e Foucault utilizam esse termo, de tal modo que promete redenção dessa classe pela educação enquanto, na verdade, possibilita transformar, com o carimbo do Estado e anuência de toda a sociedade, o abandono social em "culpa individual" de alunos supostamente burros e preguiçosos. Em nossa pesquisa, abundam declarações tocantes de jovens que se imaginam incapazes de estudo, sem inteligência e sem capacidade de concentração por culpa própria. Constrói-se a partir disso um contexto em que, tanto na dimensão intersubjetiva da interação social face a face dos sujeitos quanto na dimensão das práticas institucionais de todo tipo, sejam elas policiais, médicas ou escolares, o desvalor objetivo dos indivíduos dessa classe despossuída existencial, moral e economicamente é reafirmado cotidianamente.

O mesmo contexto de reprodução da miséria material e simbólica é o que explica, mais uma vez, a impotência política dessa classe de desclassificados. Notamos em nossa pesquisa que existe um verdadeiro abismo entre os chamados 
"pobres honestos" - aqueles que aceitam vender sua energia muscular a preço pífio - e aqueles percebidos como "pobres delinquentes" - que se revoltam reativamente contra a estrutura que os condena. Em nenhum estrato social essa diferença é tão importante e decisiva quanto na "ralé" pesquisada. O drama cotidiano da imensa maioria das famílias da "rale" - muito especialmente das mais estruturadas dentre elas - é precisamente o tema da "honestidade", percebida como a fuga do destino de bandidos para os meninos - ou do destino de "bêbados" para os adultos masculinos - e do destino de prostituta para as meninas. Essas são as figuras paradigmáticas da delinquência nessa classe que está, por sua fragilidade e pobreza, especialmente exposta aos riscos e seduções da vida desviante.

Constrói-se com isso uma divisão insidiosa e virulenta dentro dessa classe, tornando especialmente difícil qualquer forma de solidariedade interna dessa camada desprivilegiada. Como praticamente toda família ou vizinhança tinha exemplos de vidas que "optaram" pela delinquência no sentido exposto anteriormente, abundaram os relatos de mães que exploravam economicamente a filha prostituta ao passo que a acusavam pela escolha de vida, ou ainda de irmãos que não se falavam por terem optado por caminhos diferentes nas únicas duas opções possíveis para membros dessa classe. A hierarquia valorativa dominante, que pode ser exposta nos termos que viemos utilizando na oposição "digno"/ "indigno", não só transfere a culpa da "indignidade" de todos ao próprio indivíduo, mas também quebra e separa a classe como um todo e, dentro dela, cada família, cada vizinhança, e no limite cada indivíduo, em dois inimigos irreconciliáveis.

Vários desses resultados não são diferentes das pesquisas que Bourdieu realizou em subúrbios de grandes cidades americanas ou francesas. Também guardam semelhanças com pesquisas realizadas na Argélia nos anos de 1960. Mas o que não foi construído por Bourdieu foi um arcabouço teórico que, para além da análise mais contextual e histórica, permitisse captar a eficácia silenciosa da hierarquia valorativa presente nas práticas institucionais e sociais desses subúrbios como um quadro de referência comum. Existem duas vantagens associadas à construção de um quadro de referência comum para a análise de sociedades ditas avançadas e periféricas. A primeira é a superação do "racismo implícito" em toda separação substancialista que essencializa e petrifica falsas oposições ad hoc. Quando se fala de sociedades personalistas, por exemplo, movidas pela corrupção, imagina-se, necessariamente, sociedades perfeitas supostamente sem corrupção.

As diferenças de "quantidade" se transformam, por debaixo do pano e silenciosamente, em diferenças de "qualidade". Para disso se pensar, como 
efetivamente pensa o senso comum mundial em todas as dimensões da vida, em indivíduos essencialmente sujos, preguiçosos e inconfiáveis a partir de sua nacionalidade é um passo fácil de ser dado, como nos mostra o noticiário todos os dias. Esses são os seres humanos que podem morrer aos milhares, como os iraquianos ou afegãos, sem provocar grande comoção na mídia "civilizada”. Do mesmo modo, matam-se os brasileiros da "ralé" todos os dias sem qualquer incômodo das classes privilegiadas no Brasil. O processo de não reconhecimento social é o mesmo nos dois casos e ocorre pelas mesmas razões. Esse é um processo pretensamente confirmado pela legitimidade das "ciências" dominantes e conservadoras.

A outra vantagem concomitante é a possibilidade de aprendizado pela comparação refletida. Pode-se criticar muita coisa nas teorias da modernização tradicionais, e certamente a maior parte das críticas são bem dirigidas e corretas. Mas não considero errado o pressuposto de que existem sociedades "melhores", mais "justas" ou "humanas" do que outras. O erro das teorias tradicionais da modernização foi ter associado a noção abstrata de "melhor" e mais "justo" com o exemplo concreto da sociedade americana, o que certamente não é verdade em muitos aspectos importantes. Mas que o critério de melhor ou pior existe, e que este é compartilhado pela imensa maioria das sociedades modernas, é mera consequência do ponto de partida teórico desenvolvido aqui. Talvez a forma como as sociedades modernas lidam com seus desclassificados sociais seja um bom ponto de partida para esse tipo de sociologia crítica comparada da modernidade, tanto central quanto periférica.

\section{Referências}

BELLAH, R. The broken Covenant. Chicago: University of Chicago Press, 1992. BOURDIEU, P. O desencantamento do mundo. São Paulo: Perspectiva, 1979. . A miséria do mundo. São Paulo: Vozes, 2001.

COHN, G. Crítica e Resignação. São Paulo: Martins Fontes, 2003.

DAMATTA, R. Carnavais, malandros e heróis. Rio de Janeiro: Zahar, 1978.

ELIAS, N. Über den Prozess der Zivilisation II. Frankfurt: Suhrkamp, 1986.

HONNETH, A. Der Kampf um Anerkennung. Frankfurt: Suhrkamp, 1994.

HABERMAS, J. Die Theorie des kommunikativen Handelns. Volume II. Suhrkamp, 1986.

MARX, K. Das Kapital. Berlim: MEGA, 1982.

LUHMANN, N. Soziologische Aufklärung 6. Wiesbaden: VS Verlag, 2008.

PARSONS, T.; SHILLS, E. Towards a general theory of action. Harper, 1962. 
SOUZA, J. A elite do atraso. São Paulo: Leya, 2017.

A ralé brasileira: quem é e como vive. 3. Ed. São Paulo: Contracorrente, 2017.

A tolice da inteligência brasileira. São Paulo: Leya, 2015.

Patologias da Modernidade: um diálogo entre Weber e Habermas. São Paulo: Annablume, 1997.

STOCKING, G. Volksgeist as Method and Ethic: Essays on Boasian Ethnography and the German Anthropological tradition, Wisconsin, 1998.

TAYLOR, C. The Sources of the Self, Harvard, 1989.

Recebido em 27/12/2017

Aprovado em 27/04/2017

\section{Como citar este artigo:}

SOUZA, Jessé. Descolonizando o pensamento social: para ir além de Pierre Bourdieu.

Contemporânea - Revista de Sociologia da UFSCar, v. 8, n. 1, jan.- jun. 2018, pp. $139-160$ 